\title{
Geografía de las Plantas en La Alcarria Occidental y Mesa de Ocaña (II). Análisis fitoecológico y biotípico de la flora autóctona en cinco localidades representativas
}

\author{
Juan Javier GARcíA-ABAD Alonso \\ Departamento de Geografía. Universidad de Alcalá \\ juanj.garciaabad@uah.es.
}

Recibido: 29 de Noviembre de 2010

Enviado a evaluar: 3 de Marzo de 2011

Aceptado: 28 de Junio de 2011

\begin{abstract}
RESUMEN
A partir de inventarios florísticos efectuados en el año hidrológico 2002-03 en cinco cuadrículas U.T.M. de $1 \mathrm{~km}^{2}$, que forman un transecto representativo en La Alcarria Occidental y Mesa de Ocaña (AM), se continúa el análisis de espectros biológicos iniciado en un trabajo anterior (García-Abad, 2009, Parte I). Se tratan dos criterios: fitoecológico y biotípico. Los espectros obtenidos se relacionan con los correspondientes al conjunto de AM, gracias al anidamiento territorial efectuado. Los resultados, además de proporcionar una descripción cuantitativa de la flora, permiten interpretarla fitogeográfica y geoecológicamente. Casi una cuarta parte de la flora de AM corresponde a plantas arvenses, ruderales y de ambientes poco exigentes, siendo esta proporción aún mayor en la localidades analizadas. Aunque los terófitos lideran el espectro biotípico, globalmente las plantas perennes son las mayoritarias. Finalmente, se valora la pertinencia de utilizar la unidad U.T.M. de $1 \mathrm{~km}^{2}$ para estudiar la geografía de las plantas.
\end{abstract}

Palabras clave: Cuadrícula U.T.M. de $1 \mathrm{~km}^{2}$. Espectro biotípico. Espectro fitoecológico. Fitogeografía. Interpretación geoecológica. La Alcarria Occidental y Mesa de Ocaña.

Geography of plants of Western La Alcarria and "Mesa" of Ocaña (II). Phytoecological and life forms indigenous flora analysis in five representative space tracts

\begin{abstract}
Biological spectra analysis initiated in a previous paper (García-Abad, 2009, Part I) is continued here. Floristic inventories are carried out during one agricultural year (2002-03) in five $1 \mathrm{~km}^{2}$-U.T.M. grid squares. These space tracts form a representative transect in Western La Alcarria and "Mesa" of Ocaña (AM). This Part II is about the phytoecological and life forms spectra. Since the both spaces are nested local spectra could be related to the spectra of AM region. Besides providing a quantitative description of the flora, the outcomes allow to made phytogeographical and geoecological interpretations. Almost a fourth part of AM's flora corresponds to weeds, ruderals and plants that grow on other open sites, being their percentages higher in analyzed five localities. Despite the life forms spectrum shows a clear top position of the terophytes, the perennial plants dominate extensively ones. Finally, the relevancy of the $1 \mathrm{~km}^{2}$-U.T.M. grid square to study the geography of the plants is valued.
\end{abstract}

Key words: 1 km² U.T.M. grid cell. Ecological spectrum. Geoecological Interpretation. Life forms spectrum. Phytogeography. Natural region of Western La Alcarria and "Mesa" de Ocaña. 
Géographie des plantes de La Alcarria de l'Ouest et "Mesa" d'Ocaña (II). Analyse phytoécologique et des types biologiques de la flore indigène à cinq localités représentatives

\begin{abstract}
RÉSUMÉ
À partir des relevés floristiques effectués dans l'année agrologique 2002-03 à cinq carrés U.T.M. de $1 \mathrm{~km}^{2}$, formant un transect représentatif dans la región naturelle de La Alcarria de l'Ouest et "Mesa" d'Ocaña (AM), on continue l'analyse de spectres biologiques initiée à un travail antérieur (GarcíaAbad, 2009, Part I). Deux critères sont appliquées ici: phytoécologique et ceux des types biologiques. Les spectres obtenus se rattachent aux correspondants à l'ensemble d'AM, grâce à l'établissement des espaces imbriqués. En plus de fournir une description quantitative de la flore, les résultats permettent faire des interprétations phytogéographiques et geoécologiques. Près d'un quart de la flore de AM correspond aux plantes des champs, rudérales et d'autres plantes propres des environnements peu exigeants, mais les valeurs sont encore plus élevées dans les localités analysés. Bien que les thérophytes mènent le spectre des types biologiques, ce sont les plantes vivaces les plus nombreuses de l'ensemble florale. Enfin, on évalue la pertinence de l'unité UTM $1 \mathrm{~km}^{2}$ pour étudier la géographie des plantes.
\end{abstract}

Mots clef: Carré U.T.M. de $1 \mathrm{~km}^{2}$. Interprétation géoecologique. Phytogéographie. Spectre des types biologiques. Spectre phytoécologique. Region naturelle de La Alcarria de l'Ouest et "Mesa" d'Ocaña.

\title{
1. INTRODUCCIÓN
}

En dos trabajos anteriores se iniciaron estudios sobre la riqueza vascular y el espectro taxonómico de la flora autóctona de La Alcarria Occidental y Mesa de Ocaña (AM, a partir de ahora), y de cinco localidades que eran representativas de sus rasgos geográficos típicos (García-Abad, 2006 y 2009). Éstas consistieron en cinco cuadrículas U.T.M. de $1 \mathrm{~km}^{2}$ (ED50) separadas geográficamente de manera más o menos equidistante, según un criterio de selección que aportaba cierto poder predictivo, pues son típicas del paisaje alcarreño-ocañense. En conjunto muestran sintéticamente buena parte de sus gradientes climáticos, topográficos, litológicos, geomorfológicos y edafológicos. Además, la selección priorizó la presencia de ambientes zonales y/o climácicos, tratando de evitar los azonales y/o extremos. Aquellas localidades fueron las siguientes (Fig. 1): C1 (30TWL0624), municipios de Utande y Miralrío (Guadalajara); C2 (30TVK9395), Lupiana (Guadalajara); C3 (30TVK8264), Villar del Olmo y Ambite (Madrid); C4 (30TVK7136), Villarrubia de Santiago (Toledo); y C5 (30SVK6207), La Guardia (Toledo).

Los antecedentes, los rasgos geográficos de cada una de estas cuadrículas, su semblanza fitogeográfica, el método empleado, los táxones inventariados y algunas discusiones ya fueron expuestos ampliamente en García-Abad (2006 y 2009). El análisis de semejanza florística efectuado en la Parte I (García-Abad, 2009) reveló que, en un primer nivel de desagregación geográfica, C1, C2 y C3 formaban un sector centro-septentrional (pisos supra y mesomediterráneo) algo diferenciado respecto al meridional (piso mesomediterráneo), constituido por $\mathrm{C} 4$ y C5. 
Figura 1. Situación de las cinco cuadrículas de $1 \mathrm{~km}^{2}$.

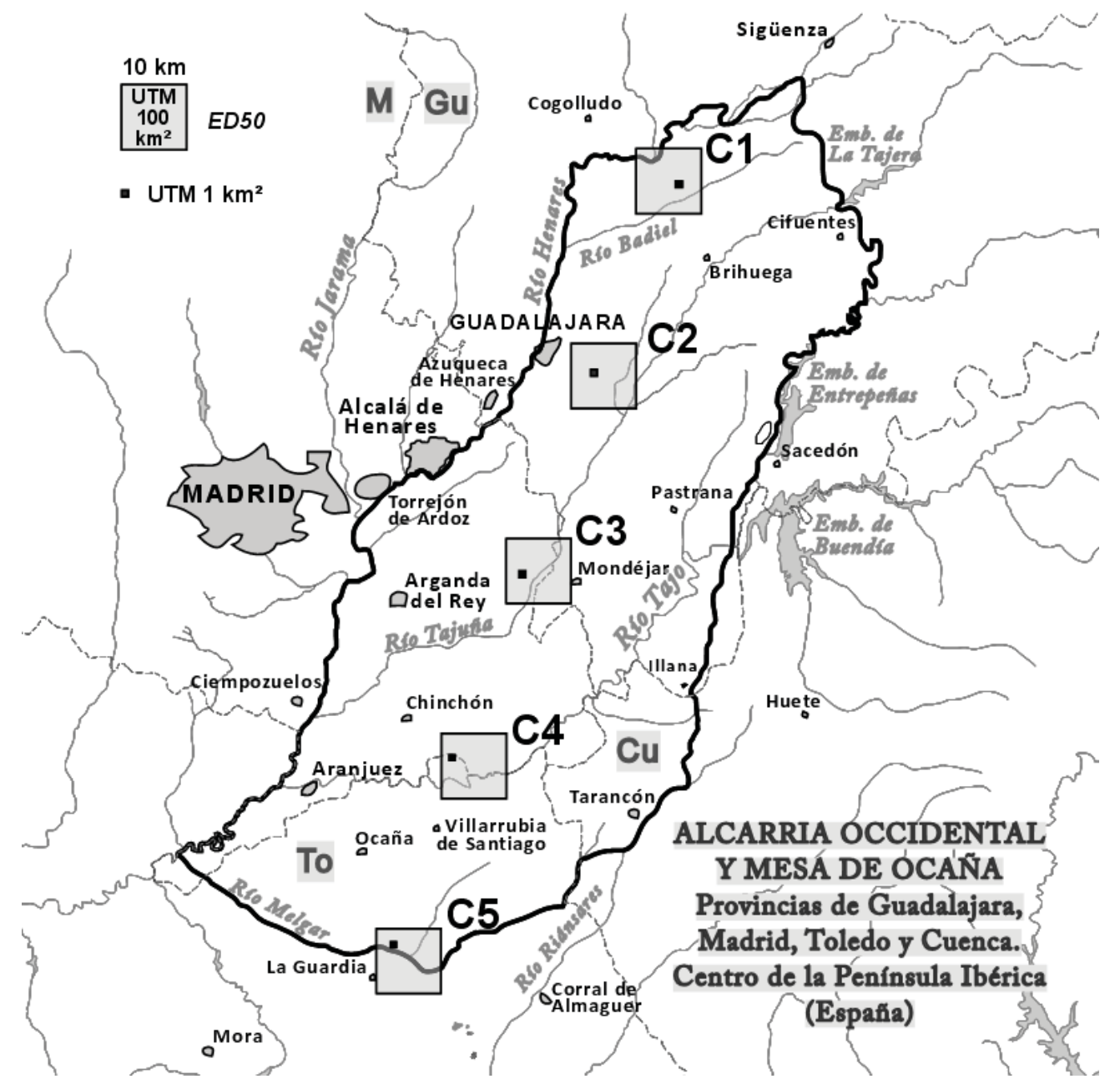

Fuente: García-Abad (2009)

Todas estas cuestiones y el estudio en general se enmarcan en dos contextos diferentes, pero solidarios y convergentes: a) el de un planteamiento clásico sobre Geografía de las Plantas que pretende, mediante análisis de espectros, la descripción cuantitativa del conjunto floral de territorios de diferente entidad; $y$ b) el de un planteamiento estratégico de recuento florístico con fines geográficos, que emplea el recinto cartográfico U.T.M. de $1 \times 1 \mathrm{~km}$ como unidad de referencia espacial.

El presente artículo continúa ambos trabajos. Por tanto, con objeto de no reiterar aspectos ya tratados, se recomienda la consulta previa de esas publicaciones para facilitar la comprensión de lo que aquí se expondrá. 
Ahora, los objetivos específicos son: a) presentar otros espectros florísticos de AM (fitoecológico y biotípicos), a partir de una base de datos que recopila diferentes fuentes (actualizada hasta IX-2008); b) presentar los mismos espectros en esas cinco localidades, a partir del trabajo de campo en un ciclo anual completo (año hidrológico 2002-03); c) comparar los espectros obtenidos e interpretarlos fitogeográfica y geoecológicamente; y d) a la luz de los resultados, comentar y discutir ventajas y desventajas del uso de la cuadrícula U.T.M. de $1 \mathrm{~km}^{2}$ para inventarios florísticos con fines geográficos.

\section{RESULTADOS}

\subsection{ESPECTRO FITOECOLÓGICO DE LA FLORA AUTÓCTONA}

Como se sabe, las plantas muestran una tendencia a reunirse en condiciones ambientales determinadas (Ozenda, 1964; Duvigneaud, 1974 -grupos socioecológicos-; Ederra, 1996; Peinado et al., 2008), existiendo un cierto grado de fidelidad entre ellas para presentarse en comunidades sinecológicas que responden a los factores del medio (Braun-Blanquet, 1928, 1979; Bolòs, 1963; Géhu y RivasMartínez, 1981; Rivas-Martínez, 2007; Peinado et al., 2008). Estas afinidades contribuyen a conocer no sólo la diversidad de ambientes existentes en un territorio (Mucina, 1997; Rivas-Martínez et al., 2001 y 2002; Alcaraz et al., 2008; Peinado et al., 2008) o a diagnosticar el estado del paisaje vegetal (Ferreras, 1987, 1990), sino que también ponen en evidencia bastantes de los rasgos autoecológicos de las plantas. Aunque científicamente sería posible establecer los rangos ecológicos de éstas (Ellenberg, 1994), resulta una labor bastante ardua (Runhaar et al., 2004; http://www.synobiosys.alterra.nl/ecotopen) y, por ello, no completada (Alcaraz et al., 2008, p. 17). Así pues, en base a todo lo expuesto y en ausencia de éstos, oriterios fitocenológicos amplios que ya están muy avanzados podrían apoyar una aproximación mediata a una eventual clasificación ecológica de las plantas. En este sentido, los comentarios y referencias de Ferreras (1990), Mayor (Prólogo en Ellenberg, 1994) y Mucina (1997) sustentan cierto grado de compatibilidad entre la posición o agrupamiento ecológico de las plantas y los sintáxones fitosociológicos.

Con ese propósito y con este criterio, la Tabla 1 tipifica fitoecológicamente la flora autóctona de AM, la del conjunto de las cinco cuadrículas (5C, a partir de ahora) y la de cada una de las cuadrículas por separado.

En un segundo nivel de tipificación, se desagregan dos de los grandes grupos fitoecológicos anteriores ( $\mathrm{Ht}$ y Ms), por su diferente apetencia a sustratos ácidos o yesosos (Tabla 2).

Los datos absolutos de las Tablas 1 y 2 se reducen en las Figuras 2 y 3 .

La flora de AM está claramente liderada, con algo más de una quinta parte, por plantas ruderal-arvenses. En segundo lugar, le sigue un agrupamiento de plantas no clasificado fitosociológicamente cuya adscripción a clases de modo restringido o excluyente es difícil, bien por su ecología amplia, parcialmente transgresiva, o no determinada ("av"). Entre otras apetencias ambientales, un 15-20\% de estas plantas podría vincularse, por convivir en ambientes nitrófilos, como complemento o 
apéndice floral de "Hrv" y, por tanto, a ese rasgo de muy baja naturalidad. Pero, en el otro extremo, incluye también un 10-15\% de plantas con requerimientos ecológicos muy exigentes. En definitiva, es una especie de "cajón de sastre" dominado por herbáceas no vivaces.

En tercer lugar, poco más de una décima parte corresponde a un grupo de plantas de muy baja talla que se sitúan en la etapa inicial o pionera natural de la sucesión vegetal ("Ht"). Mientras que el cuarto lugar (doceava parte) está protagonizado por plantas todavía predominantemente herbáceas de muy baja a baja talla, pero ya vivaces y menos xéricas, que implican una segunda etapa sucesional; o bien un escalón de cierta estabilización a ligera recomposición del medio por alteración previa ("Hm").

En quinto y sexto lugar, con cifras muy similares, se hallan dos grupos ecológicamente muy diferentes: a) plantas empradizantes, mayoritariamente hemicriptófitos, condicionadas por el aprovechamiento humano de biótopos riparios o análogos con fines pascícolas, que casi siempre indican tanto degradación ambiental como cierta o bastante humedad edáfica ("Pmh"); y b) plantas mayoritariamente leñosas (sobre todo, caméfitos), propias de los matorrales que se implantan cuando los bosques climácicos han sido degradados por acción humana, indicando una tercera etapa de recuperación del suelo tras las perturbaciones, en ambientes más o menos xéricos ("Ms").

Contrariamente, los ambientes climácicos ("Bpe" y "Bmc") o de comunidades permanentes por fuerte condicionamiento edáfico ("Hal", "Rup" y "BAe") y/o hídrico ("Dul" y "Acu"), más próximos a la madurez y a la naturalidad, aportan un contingente floral relativamente bajo. En conjunto, estas siete agrupaciones apenas superan la sexta parte de las plantas autóctonas. 
Tabla 1. $\mathrm{N}^{\mathrm{o}}$ de plantas autóctonas ${ }^{1}$ según apetencia fitoecológica más característica ${ }^{2}$

\begin{tabular}{|c|c|c|c|c|c|c|c|c|c|c|}
\hline \multicolumn{2}{|r|}{ GRANDES GRUPOS FITOECOLÓGICOS } & \multirow{2}{*}{$\frac{\mathbf{A M}^{\mathbf{3}}}{343}$} & \multirow{2}{*}{$\frac{5 C^{4}}{200}$} & \multirow{2}{*}{$\begin{array}{l}\text { C1 } \\
141\end{array}$} & \multirow{2}{*}{$\begin{array}{c}\text { C2 } \\
134\end{array}$} & \multirow{2}{*}{$\begin{array}{l}\text { C3 } \\
141\end{array}$} & \multirow{2}{*}{$\begin{array}{c}\text { C4 } \\
106\end{array}$} & \multirow{2}{*}{$\frac{\text { C5 }}{148}$} & \multirow{2}{*}{\multicolumn{2}{|c|}{$\begin{array}{rc}\mathrm{FC}^{5} & \% \\
69 & 34,5\end{array}$}} \\
\hline Hrv & Herbazales ruderales y arvenses & & & & & & & & & \\
\hline av & Ecologia amplia, variada o no determinada & 250 & 79 & 46 & 45 & 49 & 25 & 38 & 14 & 17,7 \\
\hline $\mathrm{Ht}$ & Herbazales terofiticos no nitrófilos & 174 & 70 & 42 & 46 & 52 & 49 & 49 & 30 & 429 \\
\hline $\mathrm{Hm}$ & Herbazal-matorrales mesófilos a un poco xéricos & 139 & 64 & 43 & 50 & 38 & 26 & 38 & 19 & 29,7 \\
\hline $\mathrm{Pmh}$ & Praderas meso-higrófilas antropozoógenas & 113 & 47 & 37 & 35 & 12 & 1 & 18 & 7 & 2,1 \\
\hline $\mathrm{Ms}$ & Matorrales seriales & 112 & 70 & 43 & 44 & 35 & 46 & 46 & 16 & 229 \\
\hline Snn & Veg subnemoral nitrófila a muy poco nitrófila & 88 & 32 & 21 & 18 & 13 & 8 & 10 & 2 & 63 \\
\hline Dul & Veg dulceacuicola fontanal, anfibiay turfófila & 73 & 13 & 11 & 6 & & & 4 & & 0,0 \\
\hline $\mathrm{Hal}$ & Vegetación halófila & 48 & 3 & & & & 1 & 3 & & $\dddot{0} 0$ \\
\hline Rup & Veg rupicola y/o de ámbitos muy pedregosos & 46 & 15 & 9 & 3 & 11 & 3 & 3 & & 0,0 \\
\hline Bpe & Bosques perennifolios y/o esclerófilos & 44 & 24 & 16 & 14 & 20 & 14 & 12 & 6 & 25,0 \\
\hline $\mathrm{Hbx}$ & Herbazal-matorrales basófilos abiertos y/o xéricos & 41 & 24 & 17 & 15 & 18 & 17 & 16 & 8 & 33,3 \\
\hline Asp. & Arbustedas seriales preforestales & 36 & 16 & 11 & 14 & 8 & 2 & 3 & & 0,0 \\
\hline BAe & Bosques y Arbustedas edafohigrófilos & 35 & 4 & 2 & 2 & 2 & 1 & 1 & & 0,0 \\
\hline Msn & Matorrales subnitrófilos & 31 & 16 & 11 & 8 & 10 & 7 & 12 & 4 & 250 \\
\hline Bmc & Bosques mesófilos caducifolios o marcescentes & 26 & 10 & 9 & 6 & 5 & 1 & & & 0,0 \\
\hline Acu & Vegetación acuatica & 20 & & & & & & & & - \\
\hline Oro & Herbazal-matorrales oro-criófilos & 13 & 3 & 2 & & 1 & 1 & 1 & & 0,0 \\
\hline \multicolumn{2}{|c|}{ Número de Grandes Grupos Fitoecológicos } & 18 & 17 & 16 & 15 & 15 & 15 & 16 & - & - \\
\hline \multicolumn{2}{|c|}{ Número de Plantas Autóctonas (Riqueza Vascular) } & 1634 & 690 & 461 & 440 & 415 & 308 & 402 & 169 & 24,5 \\
\hline
\end{tabular}

Fuentes: AM (García-Abad, 2006 y 2009), resto (Trabajo de Campo, año 2002-03)

Tabla 2. $\mathrm{N}^{\mathrm{o}}$ de plantas autóctonas ${ }^{1}$ según otros agrupamientos fitoecológicos ${ }^{2}$

\begin{tabular}{|c|c|c|c|c|c|c|c|c|c|c|c|}
\hline \multicolumn{2}{|r|}{ AGRUPAMIENTOS FITOECOLÓGICOS } & \multirow{2}{*}{$\frac{\mathbf{A M}}{51}$} & \multirow{2}{*}{$\begin{array}{c}\% \\
3,1\end{array}$} & \multirow{2}{*}{$\frac{5 C}{3}$} & \multirow{2}{*}{ C1 } & \multirow{2}{*}{$\begin{array}{r}\mathrm{C} 2 \\
1\end{array}$} & \multirow{2}{*}{$\frac{\mathrm{C} 3}{3}$} & \multirow{2}{*}{ C4 } & \multirow{2}{*}{$\begin{array}{r}\text { C5 } \\
1\end{array}$} & \multirow{2}{*}{ FC } & \multirow{2}{*}{$\frac{\%}{0,0}$} \\
\hline Hta & Herbazales terofiticos acidófilos o calcífugos & & & & & & & & & & \\
\hline Htg & Herbazales terofiticos gipsófilos & 9 & 0,5 & 5 & & & & 5 & 2 & & 0,0 \\
\hline Htc & Resto de Herbazales terofiticos (e calcicolas) & 114 & 7,0 & 62 & 42 & 45 & 49 & 44 & 46 & 30 & 48,4 \\
\hline Msa & Matorrales seriales ácido-neutrófilos & 14 & 0,9 & 2 & 2 & 2 & & & & & 0,0 \\
\hline Msg & Matorrales seriales gipsófilos & 16 & 1,1 & 11 & & & & 9 & 10 & & 0,0 \\
\hline Msc & Resto de Matorrales seriales ( $\approx$ calcicolas) & 82 & 5,0 & 57 & 41 & 42 & 35 & 37 & 36 & 16 & 28,1 \\
\hline
\end{tabular}

Fuentes: AM (García-Abad, 2006 y 2009), resto (Trabajo de Campo, año 2002-03)

${ }^{1}$ Táxones hasta el nivel de variedad. Igual en las Tablas siguientes.

${ }^{2}$ Basada en la adscripción de plantas a clases fitosociológicas, según Rivas-Martínez et al. (2002). Para no atomizar en exceso el análisis, en este trabajo se agrupan ad hoc en 18 grandes grupos (se indican los códigos numéricos y alfanuméricos empleados en esa obra): Acu, plantas características de los sintáxones de las clases 2, 3 y 6; Asp, 65 y 66; av, plantas sin adscripción; BAe, 70 y 71; Bmc, 76; Bpe, 74, 75 y 77; Dul, 8, 9, 11, 12 y 14; Hal, 16, 17, 19, 20, 22, 23 у 25; Hbx, 55 у 56; Hm, 51 a 54 у 57; Hrv, 34, 35, 38 у 39; Ht, 50; Hta, 50a; Htg, 50.11; Ms, 61, 62 у 64; Msa, 61 у 62; Msg, 64c; Msn, 37; y Oro, 45 y 49; Pmh, 59 y 60; Rup, 26 a 29, 32 y 33; y Snn, 40, 41 y 43.

${ }_{3}$ AM: La Alcarria Occidental y Mesa de Ocaña.

${ }^{4} \mathbf{5} \mathbf{C}=\mathrm{C} 1+\mathrm{C} 2+\mathrm{C} 3+\mathrm{C} 4+\mathrm{C} 5$.

${ }^{5}$ FC, Flora Común o número de plantas que estaban presentes en las cinco cuadrículas y porcentaje respecto a las inventariadas en 5C. NOTA: Los Grandes Grupos sombreados en la Tabla 1 son los desagregados en la Tabla 2 . 
Figura 2. Espectro fitoecológico de las plantas de La Alcarria Occidental y Mesa de Ocaña

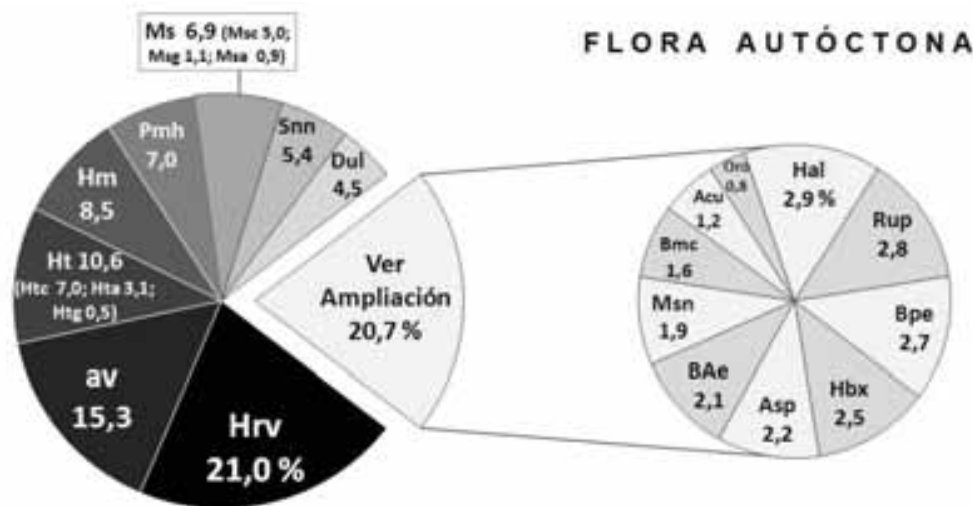

Acu, Vegetación acuatica, Asp. Arbustedas seriales pretorestales; an, Plentas de ecologia amplas, variada o no doterminada. BAe, Bosques y arbustedas edafohigrofilos, Bme, Bosq. mesofilos caducifolios o marcescenles; Bpe, Bosq. perternifolios yio

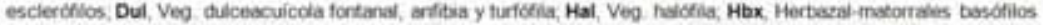
abiertos yio xécicos, Hm. Herb mat. mesofilos a un poco xiericos. Hrv. Herb nuderabes y arvanses. Ht. Herb terotiticas no

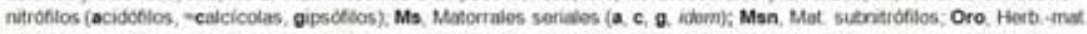
oro-criotios; Pmh, Praderas mosso-higrobias antropozodgenas; Rup, Veg rupicola yjo de ambitos muy pedregosos; Snn.

Veg subnemora nitrofla a muy poco nitrofita

Fuentes: las mismas de las Tablas 1 y 2. Elaboración propia

Figura 3. Espectros comparados de los principales grupos fitoecológicos de las cinco cuadrículas y del conjunto floral 5C (columna negra). Ht y Ms se desagregan según Tabla 2

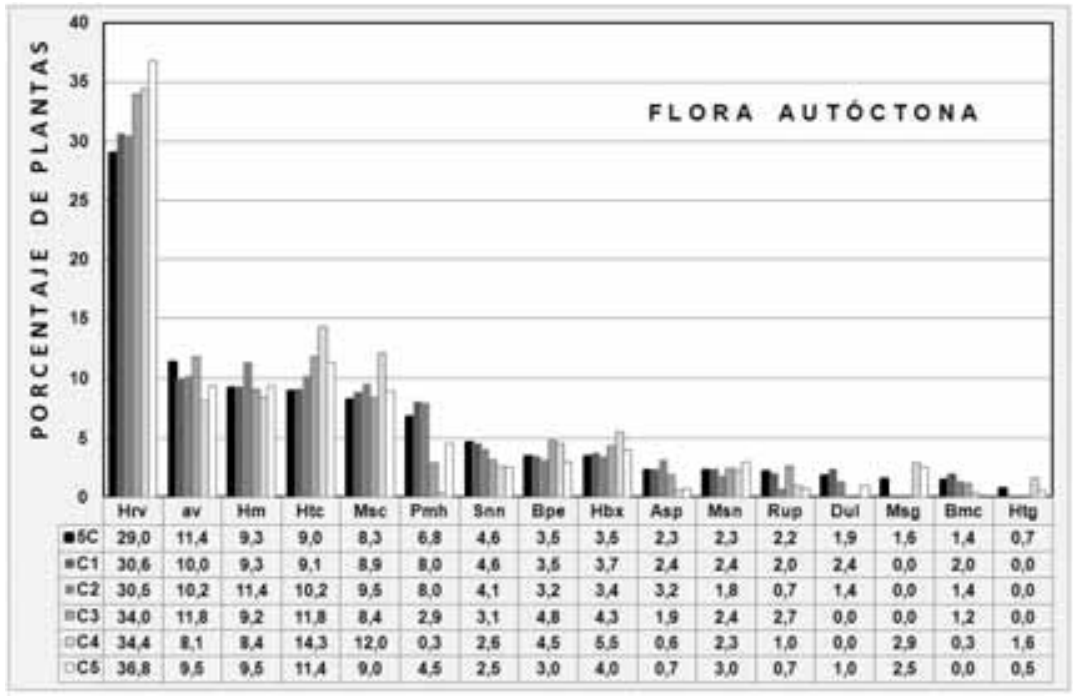

Fuente: Trabajo de Campo (año hidrológico 2002-03). Elaboración propia 
En síntesis, en casi las tres cuartas partes de la flora, el orden fitoecológico alcarreño-ocañense actual muestra el siguiente modelo (Tabla 1 y Figura 2):

$$
\mathrm{Hrv}>\mathrm{av}>\mathrm{Ht}>\mathrm{Hm}>\mathrm{Pmh} \approx \mathrm{Ms}>\mathrm{Snn}
$$

En estos siete primeros términos, el orden del modelo fitoecológico de $5 \mathrm{C}$ se parece al regional. La única excepción es que "Ms" adelanta dos posiciones.

18 grandes grupos fitoecológicos están en AM. Pero, en las cuadrículas no hay vegetación acuática ("Acu"), y "Oro", "Bmc", "BAe", "Hal" y "Dul" tienen una presencia de minoritaria a nula. Sigue destacando el liderazgo de las ruderales y arvenses (Tabla 1, Figura 3). Los porcentajes alcanzados en cada cuadrícula ( $>30 \%)$, mayores que los de AM, manifiestan la pauta de un abrumador porcentaje de plantas que delata artificialización del medio. La proporción es prácticamente progresiva hacia el Sur, evidenciándose la presencia de medios menos exigentes.

A grandes rasgos, otras variaciones marcan el gradiente geoecológico del transecto (Tabla 1). Hay una tendencia general decreciente Norte-Sur de plantas de bosques marcescentes ("Bmc") y espinosas preforestales ("Asp"). Lo mismo ocurre en herbáceas mesófilas ("Hm", "Pmh", "Snn"), debido al menor excedente hídrico e implantación boscosa hacia el Sur. En suma, los biótopos mesófilos, húmedos o frescos disminuyen o tienden a desaparecer. Opuestamente, hay tendencias Norte-Sur crecientes por la mayor xericidad del medio: a) en números absolutos, "Ht" y "Ms", y b) en porcentajes (Figura 3), "Hbx". A todo ello se unen, en C4 y C5, las "apostillas" gipsófilas ("Msg" y "Htg").

Otra nota destacada es la importante presencia de plantas propias del bosque esclerófilo ("Bpe") y de los herbazales vivaces xéricos ("Hbx") en C3, donde están cerca de la mitad de las plantas características de AM de estos agrupamientos (Tabla 1). En porcentajes, $\mathrm{C} 4$ se une a estos caracteres fitoecológicos, pese a su baja riqueza. La posición centro-meridional de ambas cuadrículas quizás pudiera indicar óptimos biogeográficos de estas agrupaciones dentro de la región (Figura 3).

Es curiosa la presencia de plantas acidófilas en AM, por tratarse de un territorio con sustratos básicos dominantes (Tabla 2). Sin embargo, existen reductos e isleos ácidos, por razones geoecológicas diversas, que permiten una modesta implantación de este tipo de plantas. La "exclusión" por acidofilia es mediana en las plantas anuales por su modesto aparato radicular, pero severa en las leñosas. En todo caso, la presencia de estos elementos en las cuadrículas analizadas es anecdótica. En cuanto a los gipsófitos, su número es relativamente reducido, pese a la extensión amplia que ocupan sus formaciones en AM (Ruiz de la Torre, 1996a, b y c). Sólo en C4 y C5 se hallan más de la mitad de las plantas de este tipo en AM, lo que indica una fuerte concentración espacial en los biótopos que propician su implantación.

Las columnas de Flora Común (FC, Tablas 1 y 2) aportan información de interés para deslindar qué conjuntos florístico-ecológicos se mantienen más o menos deslavazados espacialmente. El balance global de los datos muestra que, pese a lo escueto de la muestra, las plantas autóctonas comunes en las cinco localidades representan algo más de una décima parte de toda la flora regional. Por tanto, buena parte de este contingente contribuye a homogeneizar florísticamente AM. 
Si estas proporciones se discriminan fitoecológicamente, se observan las agrupaciones cuyos componentes florísticos aparecen más próximos en poco espacio. Destacan sobremanera los terófitos pioneros calcícolas ("Htc"), pues se acerca a la mitad el número de las que son comunes en las cinco localidades. Las dos agrupaciones que siguen, "Hrv" y "Hbx", alcanzan también una proporción nada desdeñable de cohesión espacial: un tercio de $5 \mathrm{C}$. La segunda es poco relevante en cuanto a riqueza, pero no así la primera, pues las 69 plantas ruderal-arvenses comunes que aparecen en las cinco cuadrículas sólo ellas suponen ya el $20 \%$ de todas las "Hrv" presentes en AM y el 4,2\% del conjunto florístico regional.

Esta Flora Común opera a modo de índice de semejanza sólo para el conjunto $5 \mathrm{C}$. Por ello, para entender mejor el significado modélico que dentro de AM poseen esas agrupaciones en muestras locales típicas, debe efectuarse la semejanza florística entre cada par de cuadrículas. El Índice de Jaccard, ya empleado en García-Abad (2009), se aplica ahora entre las plantas de cada agrupación. La Figura 4 muestra las doce más significativas.

Figura 4. Semejanza florística de grupos fitoecológicos entre cuadrículas. Aparecen en orden decreciente relativo, según media de la semejanza de los 10 pares de cuadrículas (rombos negros). En barras se indican valores máximo, mínimo y pares implicados. En "Bmc" el valor mínimo implica por igual a todos los pares de $\mathrm{C} 5$

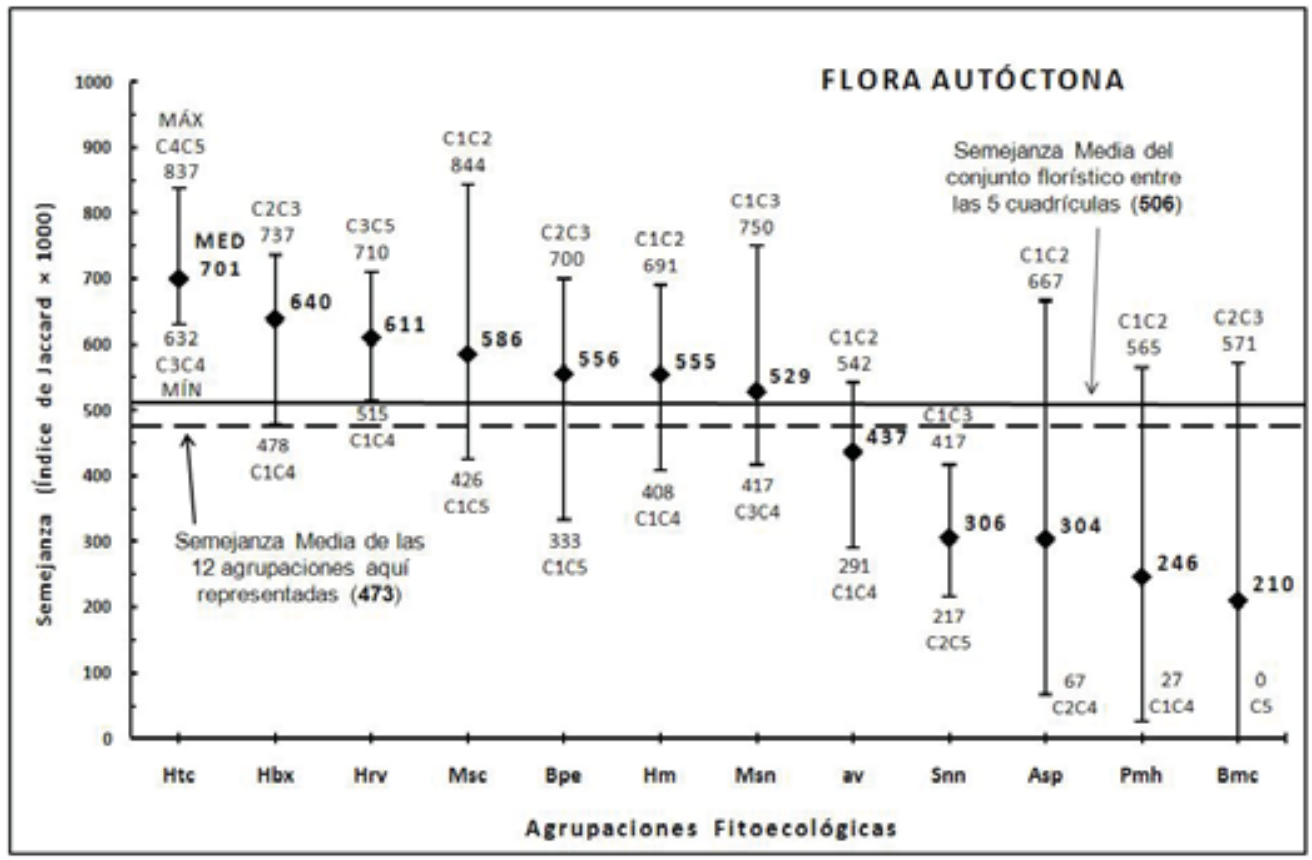

Fuente: Trabajo de Campo (Año hidrológico 2002-03). Abreviaturas: Véanse Tablas 1 y 2, y Figura 2. Elaboración propia. 
El gráfico desvela pautas de implantación local de los componentes florísticos de AM, de acuerdo a su diversidad ambiental típica. En primer lugar, discrimina el orden de los agrupamientos fitoecológicos según su particular grado de semejanza (lectura de izquierda a derecha). En segundo lugar indica los siete que, estando por encima (lectura arriba y abajo de las líneas de medias), contribuyen más a la semejanza conjunta; $y$, frente a ellos, cuáles aportan disimilitud o heterogeneidad florística. En tercer lugar, la longitud de la barra informa de su amplitud interna o variación de la semejanza entre las cinco cuadrículas; es decir, una especie de coherencia (si es corta) o incoherencia (larga) en contribuir en el mismo sentido a una mayor o menor semejanza del conjunto florístico de las cuadrículas.

Los tres grupos más semejantes son los tres que también lideraban la Flora Común, teniendo los terófitos pioneros no nitrófilos de "Htc" nuevamente la primacía. En éstos, destaca el gran parecido de C4 y C5, lo que explica en parte la cohesión florística de estas cuadrículas más plenamente mesomediterráneas. También se pone de manifiesto la contrapartida: una mayor disimilitud relativa entre $\mathrm{C} 3$ y $\mathrm{C} 4$ que, por su vecindad, indica claramente una marcada cesura florística entre las cuadrículas centro-septentrionales y las meridionales. Ésta es marcada también por las plantas propias de los matorrales subnitrófilos ("Msn").

Pero lo más sobresaliente, sin duda, es el importante papel que las plantas ruderalarvenses desempeñan en la homogeneidad florística de la región. En este sentido, concurren tres rasgos definitivos: es el grupo fitoecológico de mayor riqueza florística, el tercero en semejanza media, y el de menor amplitud interna. En suma, territorialmente aportan cohesión florística. Las plantas propias de los matorrales seriales calcícolas ocupan el cuarto lugar. Sin embargo, internamente es un grupo bastante variable, pues posee el valor máximo más alto de todas las combinaciones posibles, mientras que su valor mínimo está por debajo de las medias de semejanza. Además, éste se ajusta a una "lógica" biogeográfica que, dependiente de la escala, no siempre es efectiva: máxima disimilitud entre las localidades más alejadas (Nekkola y White, 1999). Esta cualidad sólo es compartida con las plantas propias de los bosques perennifolios y/o esclerófilos.

Los cuatro grandes grupos fitoecológicos más mesófilos $(\approx 15 \%$ de la flora de 5C) presentan la menor semejanza media, lo que evidencia cómo los táxones más sensibles al aumento de xericidad inciden en la disimilitud florística general de AM. Este hecho es muy evidente entre las cuadrículas septentrionales frente a las meridionales. Sin embargo, entre las tres cuadrículas centro-septentrionales, "Asp" y "Bmc" todavía contribuyen a cierto grado de cohesión florística; mientras que "Pmh" lo hace entre las dos septentrionales.

\subsection{ESPECTRO BIOTÍPICO DE LA FLORA AUTÓCTONA}

La Tabla 3 tipifica las formas vitales establecidas por Raunkiaer $(1905,1934)$ y que, según este botánico danés, determinan el espectro biológico de una región. En general, la prolongada sequía propicia estructuras vegetales más pequeñas sobre el 
suelo (máxima expresión, en terófitos), mientras que la sequía estacional hace que otras plantas sobrevivan con órganos subterráneos o semillas durmientes (geófitos).

Los datos absolutos de la Tabla 3 se simplifican ${ }^{6}$ y reducen en las Figuras 5 y 6.

Tabla 3. Número de plantas autóctonas por biótipos ${ }^{7}$

\begin{tabular}{|l|c|c:ccccc:cc|}
\hline BIÓTIPOS $^{8}$ & AM & $\mathbf{5 C}$ & $\mathbf{C 1}$ & $\mathbf{C 2}$ & $\mathbf{C 3}$ & $\mathbf{C 4}$ & $\mathbf{C 5}$ & $\mathrm{FC}$ & $\%$ \\
\hline $\mathrm{T}$ & 576 & 257 & 168 & 157 & 179 & 141 & 168 & 87 & 33,9 \\
\hline $\mathrm{H}$ & 462 & 179 & 122 & 125 & 87 & 50 & 89 & 31 & 17,3 \\
\hline $\mathrm{C}$ & 165 & 88 & 57 & 54 & 51 & 50 & 60 & 23 & 26,1 \\
\hline H-T & 105 & 53 & 37 & 33 & 35 & 24 & 31 & 14 & 26,4 \\
\hline G & 104 & 33 & 25 & 20 & 22 & 12 & 17 & 4 & 12,1 \\
\hline Nf & 43 & 15 & 11 & 11 & 10 & 6 & 7 & 2 & 13,3 \\
\hline C-H & 36 & 10 & 7 & 4 & 6 & 5 & 6 & 2 & 20,0 \\
\hline Hdy P & 35 & 3 & 2 & 1 & & & & & 0,0 \\
\hline Mif-Nf & 29 & 12 & 8 & 8 & 8 & 5 & 5 & 1 & 8,3 \\
\hline Mif & 27 & 9 & 5 & 6 & 4 & 4 & 2 & 1 & 11,1 \\
\hline C-Nf & 20 & 13 & 6 & 8 & 6 & 8 & 9 & 2 & 15,4 \\
\hline G-H & 9 & 5 & 5 & 4 & 3 & 1 & 3 & 1 & 20,0 \\
\hline Msf & 7 & 2 & & 2 & 1 & 1 & 1 & & 0,0 \\
\hline Hd-H1 & 6 & 3 & 3 & 1 & & & 1 & & 0,0 \\
\hline L & 5 & 5 & 2 & 4 & 3 & 1 & 1 & 1 & 20,0 \\
\hline Hl & 5 & 3 & 3 & 2 & & & 2 & & 0,0 \\
\hline
\end{tabular}

Fuentes: AM (García-Abad, 2006 y 2009), resto (Trabajo de Campo, año 2002-03)

${ }^{6}$ La simplificación consiste en contabilizar el $50 \%$ de las plantas ambivalentes (con guión) para cada uno de los dos componentes, teniendo en cuenta que Nf, Mif y Msf se agrupan como F (Fanerófitos). Esta operación permite la comparación aproximada con otros territorios, pues en la bibliografía los biótopos aparecen habitualmente por separado.

${ }^{7}$ Táxones hasta el rango de variedad. Biótipos según adaptación de Rivas-Martínez (2007).

${ }^{8}$ Abreviaturas: Las de la Tabla 1 y, además: C, Caméfitos; G, Geófitos; H, Hemicriptófitos; Hd, Hidrófitos; Hl, Helófitos; L, Lianas; Mif, Microfanerófitos; Msf, Mesofanerófitos; Nf, Nanofanerófitos; P, Pleustófitos y T, Terófitos. La consulta de varias floras muestra que la adscripción de una planta a uno u otro biótipo es complicada. Smith (1913) ya señalaba esta dificultad que, a veces, se ha solventado empleando categorías de transición (Velarque et al., 2001). Por ello, hemos ha preferido mantener, al menos en esta Tabla de datos absolutos, las ambivalencias transicionales. Así, cuando aparecen dos abreviaturas separadas por guión, significa que se trata de plantas que pueden presentarse con ambos biótipos, bien que poseen caracteres intermedios, bien que son plantas con longevidad variable según el medio. Además, por otra parte, ello pone en evidencia las situaciones de formas vegetativas transicionales que son reflejo de la existencia de gradientes geográfico-ambientales. 
Figura 5. Espectro Biotípico de las plantas de La Alcarria Occidental y Mesa de Ocaña

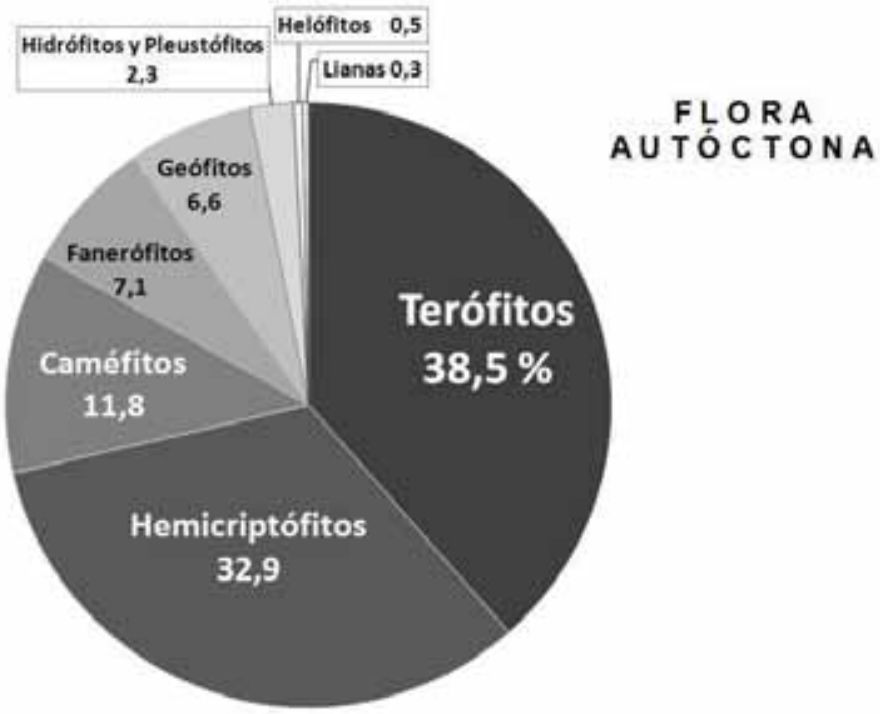

Fuentes: las de la Tabla 3. Elaboración propia

Figura 6. Espectros biotípicos comparados de las cinco cuadrículas y del conjunto floral 5C (columna negra)

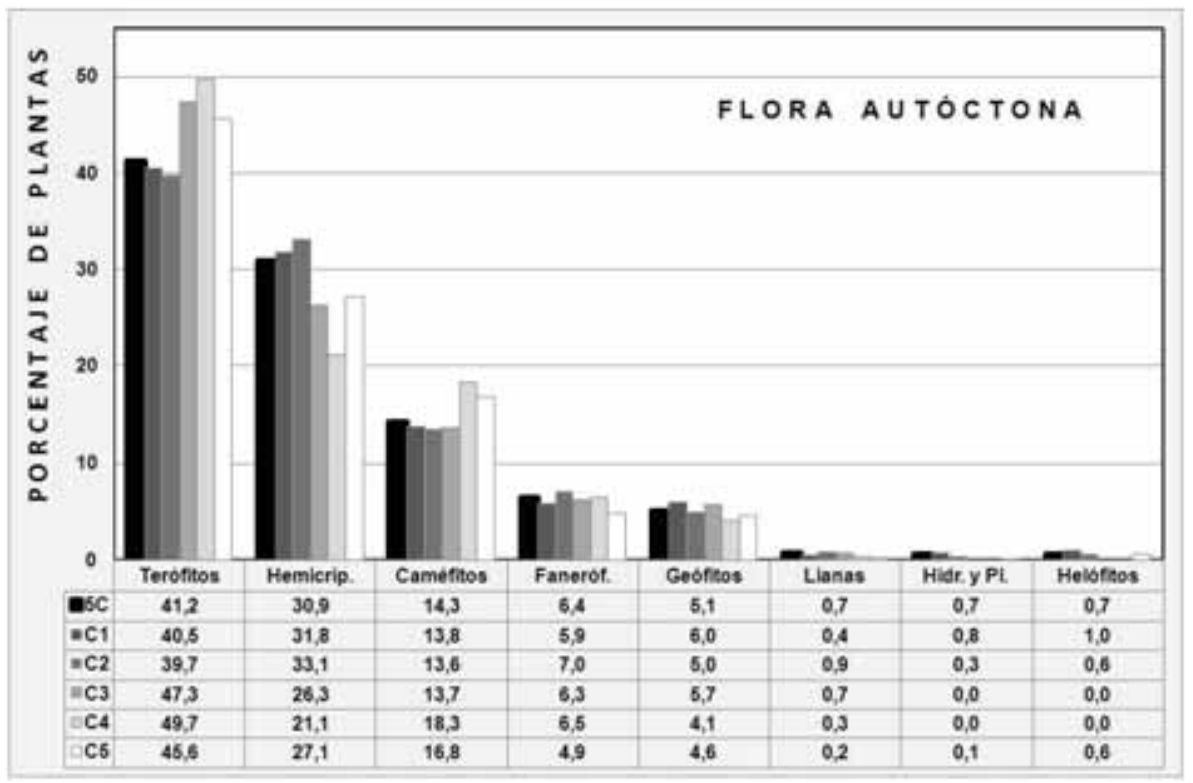

Fuentes: las de la Tabla 3. Elaboración propia 
Hay un gran parecido de cifras entre $\mathrm{C} 1$ y C2, por un lado; y $\mathrm{C} 3$ y C5, por otro. En ambos casos, los terófitos son los que más difieren, aunque no mucho en proporción. Entre C1 y C3, sólo es notable el desajuste en hemicriptófitos. En C3 se detecta el mayor número de terófitos. La razón es que, por su situación en el centro, actúa de intersección albergando algunos elementos terofíticos propios del conjunto altoalcarreño junto con algunos otros diferenciales del conjunto meridional.

Con la referida simplificación, el modelo biotípico que caracteriza AM es:

$$
\mathrm{T}>\mathrm{H}>\mathrm{C}>\mathrm{F}>\mathrm{G}>\mathrm{Hd} \text { y } \mathrm{P}>\mathrm{Hl}>\mathrm{L}
$$

Este modelo básicamente coincide en $5 \mathrm{C}$ y en todas las cuadrículas, con excepción de que en $\mathrm{C} 1$ fanerófitos y geófitos están prácticamente igualados. El dominio de terófitos es notable, debido a la típica sequía estival mediterránea. Aunque los valores absolutos, entreverados por los niveles de riqueza, no lo muestran; los relativos sí revelan un aumento del porcentaje de las plantas anuales en la particular composición florística de las cuadrículas centro-meridionales, donde por la más prolongada sequía constituyen casi la mitad de la flora. Los hemicriptófitos constituyen un tercio de la flora de AM pues, aunque muy levemente, el norte de la región tiene cierto carácter montano. $\mathrm{C} 1$ y $\mathrm{C} 2$, como contrapartida al contingente terofítico, dan buena cuenta de ello. A más distancia, están los grupos de plantas leñosas, que apenas alcanzan un quinto de la flora en 5C. Dado el clima de AM, el porte subarbustivo de baja talla de los caméfitos permite superar muy ampliamente a los fanerófitos. En términos relativos, C4 y C5 son más camefíticas que las cuadrículas centro-septentrionales, compensando la menor proporción de hemicriptófitos y geófitos. C5 ostenta un "récord" biotípico, pues tiene más de un tercio de todos los caméfitos conocidos en AM. El número de las plantas de mayor biomasa (Nf, Mif y Msf), mayor en C2 y C1, se reduce hacia el Sur progresivamente. También hay algunos geófitos más en las localidades centro-septentrionales respecto a las meridionales. En éstas, la mayor xericidad del medio hace que la flora se decante más claramente terofítica, dejando menos opciones al paso geofítico intermedio. El resto de biótipos son muy minoritarios.

En cuanto a la Flora Común, con los datos no simplificados de la Tabla 3 son los terófitos, precisamente el biótipo más numeroso, los que más contribuirían a la semejanza florística de 5C. Más que los hemicriptófitos, que sería un componente florístico bastante discordante en este sentido. Si se atiende a la secuencia $\mathrm{T} \rightarrow \mathrm{HT} \rightarrow \mathrm{H}$, se observa un descenso gradual de semejanza según se pasa de elementos herbáceos anuales a los bienales-vivaces. Y los geófitos acrecentarían aún más la disimilitud. Las plantas leñosas apuntan a una misma tendencia, según aumenta su biomasa. Si se atiende ahora a la secuencia $\mathrm{C} \rightarrow \mathrm{CNf} \rightarrow \mathrm{Nf} \rightarrow$ MifNf, se evidencia que la disimilitud se acrecentaría progresivamente también en ese sentido.

\subsection{OTROS CARACTERES VITALES}

Aunque los biótipos del sistema de Raunkiaer aportan datos sobre formas vitales y tipos morfológicos de las plantas, una exposición más analítica de esos caracteres puede ampliar, matizar o complementar la información que aquéllos proporcionan. 
Así, la base de datos recopilada incluye un diagnóstico de cada planta sobre su tipo de desarrollo vegetativo. La Tabla 4 muestra los caracteres más destacados. Éstos se presentan en tres bloques: el primero aporta datos sobre la pervivencia de la planta, el segundo sólo atañe a la deciduidad/sempervirencia foliar de los fanerófitos estrictos, y el tercero trata caracteres morfológicos, vegetativos y de consistencia.

Tabla 4. Número de plantas autóctonas según caracteres vitales y vegetativos ${ }^{9}$

\begin{tabular}{|c|c|c|c|c|c|c|c|c|c|c|}
\hline \multicolumn{2}{|r|}{ CARACTERES $^{10}$} & AM & $5 \mathrm{C}$ & C1 & $\mathrm{C} 2$ & $\mathrm{C3}$ & $\mathrm{C} 4$ & C5 & FC & $\%$ \\
\hline pe & Perennes (siempre o casi siempre) & 874 & 351 & 238 & 227 & 183 & 132 & 185 & 62 & 17,7 \\
\hline $\mathrm{bi}$ & Bienales (siempre o casi siempre) & 84 & 40 & 25 & 29 & 26 & 14 & 24 & 9 & 22,5 \\
\hline abp & Anuales bienal-perennizantes & 93 & 42 & 30 & 27 & 27 & 21 & 25 & 11 & 26,2 \\
\hline an & Anuales & 576 & 257 & 168 & 157 & 179 & 141 & 168 & 87 & 33,9 \\
\hline cf & Caducifolias & 58 & 19 & 12 & 13 & 9 & 3 & 7 & 1 & 5,0 \\
\hline $\operatorname{scp}$ & Semicaducifolias/Subperennifolias & 7 & 5 & 3 & 3 & 5 & 3 & 3 & & 0,0 \\
\hline $\mathrm{pf}$ & Perennifolias & 41 & $14:$ & 9 & 11 & 9 & 10 & 5 & 3 & 21,4 \\
\hline e & Erectas (aplicado a T y H-T) & 481 & 225 & 149 & 143 & 162 & 123 & 151 & 75 & 33,3 \\
\hline es & Escaposas (aplicado a $\mathrm{H}$ y $\mathrm{H}-\mathrm{T}$ ) & 230 & 105 & 71 & 75 & 57 & 34 & 57 & 21 & 20,0 \\
\hline ri & Rizomatosas & 209 & 66 & 52 & 44 & 22 & 11 & 26 & 6 & 9,1 \\
\hline c & Cespitosas & 206 & 73 & 55 & 43 & 43 & 35 & 39 & 23 & 31,5 \\
\hline sf & Sufruticosas (o/y fruticulosas) & 172 & 97 & 60 & 58 & 56 & 53 & 64 & 26 & 26,8 \\
\hline a & Arrosetadas o rosuladas & 161 & 67 & 46 & 42 & 31 & 27 & 34 & 13 & 19,4 \\
\hline $\mathrm{r}$ & Reptantes a postrado-decumbentes & 159 & 67 & 39 & 40 & 36 & 28 & 40 & 12 & 17,9 \\
\hline fr & Fruticosas & 126 & 51 & 31 & 35 & 27 & 26 & 24 & 6 & 11,8 \\
\hline sfl & Sufruticulosas (cepa leñosa) & 71 & 28 & 23 & 18 & 17 & 7 & 11 & 3 & 10,7 \\
\hline s & Suculentas (y crasiúsculas) & 49 & $15:$ & 7 & 9 & 9 & 5 & 9 & 1 & 6,7 \\
\hline 1 & Lianoides, pero no lianas & 42 & $20:$ & 15 & 14 & 12 & 8 & 10 & 6 & 30,0 \\
\hline en & Enraizantes o radicantes & 42 & 16 & 10 & 6 & & & 3 & & 0,0 \\
\hline $\mathrm{b}$ & Bulbosas & 40 & 14 & 8 & 8 & 10 & 8 & 10 & 2 & 14,3 \\
\hline $\mathrm{rt}$ & Radicituberiformes & 33 & 10 & 9 & 9 & 7 & 3 & 4 & 2 & 20,0 \\
\hline $\mathrm{p}$ & Parásitas y hemiparásitas & 18 & 7 & 5 & 6 & 6 & 2 & 4 & 2 & 28,6 \\
\hline su & Sumergidas & 15 & 1 & 1 & & & & 1 & & 0,0 \\
\hline $\mathrm{pu}$ & Pulviniformes & 8 & 1 & 1 & 1 & & & & & 0,0 \\
\hline $\mathrm{fl}$ & Acuáticas flotantes & 2 & & & & & & & & 0,0 \\
\hline
\end{tabular}

Fuentes: AM (García-Abad, 2006 y 2009), resto (Trabajo de Campo, año 2002-03) ${ }^{10}$

${ }^{9}$ Táxones hasta el rango de variedad. Como no siempre hay acuerdo firme en la bibliografía botánica, existen ambivalencias naturales que no permiten precisar límites categóricos. El Bloque Superior, ordenado de mayor a menor permanencia, admite balance en las cifras (AM cuadra si se añaden 7 plantas cuyo carácter es incierto o no determinado). El Bloque Intermedio se ha aplicado a los biótipos Nf, Mif-Nf, Mif y Msf de la Tabla 3. En el Bloque Inferior, ordenado de mayor a menor contingente florístico en AM, debe advertirse que las plantas pueden tener uno o varios de esos caracteres, combinados de diferente manera, y sin que bastantes de ellos sean excluyentes entre sí. Así pues, no admite balance conjunto.

${ }^{10}$ Se siguen las atribuciones de Castroviejo (1986-2008) y Bolòs y Vigo (1984-2001), y nomenclatura de Rivas-Martínez (2007). En algunas pocas ocasiones, se han hecho modificaciones según los datos y experiencia recabados en el área de estudio. 
La duración de la vida de los vegetales presenta situaciones acotadas, en principio, por el cumplimiento anual, bienal o superior de su desarrollo vegetativo completo. Pero algunos táxones pueden presentar variantes, a veces territoriales, por las que alarguen o acorten en diferente grado su persistencia vital. Aquellas acotaciones, de ser rígidas, pasan a situaciones graduales que han sido sintetizadas en cuatro categorías. Las plantas perennes o vivaces dominan el espectro alcarreño-ocañense $(53,5 \%) \mathrm{fr}$ ente a las no perennes ("bi", "abp" y "an"). Dentro de éstas, en situación intermedia, las plantas bienales ocupan un corto segmento $(5,1 \%)$ frente a las anuales y sus variantes $(40,9 \%)$. Sin embargo, esta pauta regional de mayoría vivaz sólo es cumplida por las dos cuadrículas septentrionales $(>51 \%)$, pues las tres centro-meridionales la invierten por el liderazgo de las anuales $(\geq 48 \%)$. Básicamente, el aumento de la aridez está detrás de tal inversión. C4 presenta la mayor diferencia entre anuales $(52,6 \%)$ y perennes $(42,9 \%)$, y el menor porcentaje de bienales $(4,5 \%)$. En el otro sentido, C2 tiene el mayor porcentaje de bienales $(6,6 \%)$ y el menor de anuales $(41,8 \%)$. La flora común del conjunto florístico en $5 \mathrm{C}$ disminuye gradualmente según las plantas adquieren mayor durabilidad vital.

El importante número regional de fanerófitos meso-higrófilos, vinculados a ámbitos azonales, explica la mayoría de caducifolias (54,7\%). En el transecto 5C, se aprecia ligeramente la escasísima representación de aquel tipo fitoecológico. Aparte de este balance, lo más destacado es el descenso de caducifolias hacia el Sur y el hecho de que, atendiendo a la flora común, es muy evidente la gran disimilitud florística que aportan en $5 \mathrm{C}$.

El análisis del último bloque es plural por el número y tipo de caracteres contemplados. Pero, en general, en casi todos los casos $5 \mathrm{C}$ sigue un modelo análogo al de AM en cuanto al porcentaje de plantas involucrado. Dejando de lado las claras excepciones en caracteres de muy baja frecuencia y ambientes muy especiales (plantas sumergidas, flotantes y pulviniformes), tan sólo se aprecian ligeras disparidades respecto al modelo regional en las plantas sufruticosas ("sf'), con mayor peso en $5 \mathrm{C}$, $\mathrm{y}$ en las radicituberiformes ("rt"), con menor peso.

La flora significativamente más común en $5 \mathrm{C}$ está liderada claramente por las herbáceas erectas. Tras este grupo, sólo merecen reseñarse las cespitosas y sufruticosas como elementos que contribuyen a una mayor semejanza florística.

Algunos de los caracteres expuestos pueden considerarse aisladamente, como son la heterotrofía o no plena autotrofía ("p") y la existencia de plantas suculentas ("s"). En ambos casos, las cifras absolutas marcan un bajo número en AM y no se evidencia tendencia clara dentro del transecto $5 \mathrm{C}$. Merece destacarse que el porcentaje de plantas tipo "p" en AM viene a coincidir con el 1\% que aproximadamente se da en el conjunto de las angiospermas (López-Sáez et al., 2002).

Sin embargo, otros caracteres admiten un análisis combinado. Por un lado, los relativos al tipo de tallo-ramaje. Sobresale el alto contingente de las herbáceas erguidas ("e") en el conjunto floral alcarreño-ocañense, que en términos relativos aumentan su porcentaje de participación en la flora de las cuadrículas centro-meridionales. Opuestamente, las hierbas perennes o perennizantes escaposas ("es") tienen mayor proporción en el espectro de las cuadrículas septentrionales. Igual tendencia se ob- 
serva en las lianoides ("l"), adaptación que adoptan algunas plantas que medran en ambientes boscosos.

Aspectos morfológicos protectores como los de plantas arrosetadas ("a") y cespitosas ("c") no son muy raros (más de un $20 \%$ de la flora de AM). Las primeras tienen un mayor porcentaje en las cuadrículas septentrionales respecto al resto, pero las segundas sólo despuntan en el extremo septentrional (C1).

En cuanto a la consistencia por la diferente extensión de la lignificación en el tallo, se muestra que es mayor el número de plantas fruticosas ("fr") en las cuadrículas septentrionales, donde la producción de biomasa vegetal se ve menos mermada por limitantes climáticos. Este hecho, sin embargo, no se traduce de la misma manera en términos relativos, cosa que sí ocurre con las sufruticosas ("sf”), pues más del $15 \%$ de las plantas poseen este carácter en las cuadrículas meridionales, porcentajes mayores que en el resto. En cuanto a la lignificación de las cepas de la base de las plantas ("sfl"), destaca como propiedad que van adquiriendo algunos hemicriptófitos, sobre todo según se avanza hacia el Norte de la región, siendo un fenómeno menos frecuente en las cuadrículas meridionales.

Por último, resta tratar las plantas perennes o perennizantes que poseen órgano perdurante subterráneo, más o menos engrosado ("b", "ri" y "rt"). Globalmente, son más frecuentes en las cuadrículas septentrionales ( $>13,5 \%$ de su flora), pues es el frío el principal obstáculo a esquivar. Aunque, contrariamente, a veces puede ser el calor la objeción que propicie tal estrategia, pues en las cuadrículas centro-meridionales estas plantas constituyen todavía un poco menos del 10\%.

Se cumple la primera tendencia geográfica en las plantas rizomatosas ("ri”). En las radicituberiformes ("rt"), mucho menos numerosas, C3 se une más bien a las cuadrículas norteñas. Sin embargo, en el grupo de las estrictamente bulbosas ("b"), bastantes de ellas prefieren evitar la estación fría y, en términos relativos, su porcentaje es mayor en las cuadrículas centro-meridionales.

\section{DISCUSIÓN Y CONCLUSIONES}

En Geografía de las Plantas, para determinar las áreas de distribución, es recomendable emplear unidades espaciales normalizadas de igual forma y tamaño que, extendidas sistemáticamente, cubran el espacio geográfico. Tienen la ventaja de ser regulares, permanentes y actualizables en el tiempo. A partir del inventario en cada una de ellas, se hace posible la confección de mapas corológicos. Éstos, que reflejan las distribuciones discriminadas, permitirán establecer después sectorizaciones florísticas (García-Abad et al., 2010). Progresivamente, según crezca el área prospectada, se podrían establecer también territorios florísticos.

Es inherente a este tipo de unidades, como es el caso de cuadrículas U.T.M., el que nunca o casi nunca coincidan en diversidad geoecológica y, consecuentemente, los biótopos, comunidades vegetales y plantas que aparecen en ellas sean más o menos diferentes de unas a otras. Además, internamente cada unidad no es completamente homogénea ambientalmente, pudiendo ser desde casi homogénea 
hasta muy heterogénea. Entre ellas también difieren unas de otras, pudiendo a su vez diferir poco o mucho.

Si con fines geográficos, se pretende inventariar las plantas empleando este tipo de unidades (García-Abad, 2006), los proyectos de cartografía corológica en ámbitos locales, comarcales o de conjunto en AM precisan testar la variabilidad que presentan aquéllas, pulsar el alcance que tendría el uso de muestreos y conocer el rango de riqueza vascular esperable y, por último, tener en cuenta la heterogeneidad geográfica del territorio. Con estos propósitos, el presente trabajo constituye un estudio piloto que busca algunas de esas respuestas, así como hacer comparaciones en la medida de lo posible.

En un análisis así planteado, se ha acudido a algunas estrategias que minimicen el inconveniente aludido de la heterogeneidad ambiental entre cuadrículas. Una ha sido cuidar criterios de semejanza geográfica en la selección de esos recintos territoriales. Para un tamaño de $1 \mathrm{~km}^{2}$, la semblanza fitogeográfica de cada cuadrícula muestreada (García-Abad, 2009) ayuda a calibrar el grado y alcance de la comparación planteada en este trabajo. Además, en otro (García-Abad et al., 2010) se ha observado que en una región con las características geográficas y pautas paisajísticas de AM (Tello, 1986; Asensio et al., 1991; García-Abad, 2006; García-Abad y Panareda, 2007-08; Calonge y Rodríguez, 2008), pequeños agregados de aquel tamaño se ajustan relativamente bien a la escala de orden V a VI de la clasificación geomorfológica de Tricart (1965), que incorpora la influencia de las formas del relieve en la flora y la vegetación.

La otra estrategia ha sido emplear una clasificación ecológica de las plantas que están presentes en esas unidades espaciales. Esto permite dilucidar, cualitativamente cuando menos, qué tipos de ambientes incluye y, por tanto, discriminar factores que ayuden a explicar el contingente florístico avistado. De este modo, pueden hacerse comparaciones aproximadas.

En efecto, las Tablas 1 y 2 muestran que el "capricho cartográfico" no ha incluido exactamente los mismos ambientes en las cuadrículas. Pero, si se ponderan los ligeros desajustes, resultan bastante evidentes las pautas geográfico-ecológicas representativas de la flora de AM, tanto en los niveles generales de riqueza como en las proporciones de los espectros biológicos.

Otra razón que apoya esta comparación geográfica ponderada es el alto grado de representatividad obtenido en los inventarios respecto a la unidad continente (AM), evidenciado por el anidamiento territorial. Ello se pone de manifiesto tanto en el alto porcentaje de plantas avistadas en las cuadrículas y en 5C (García-Abad, 2006 y 2009), como en el gran parecido de los modelos fitoecológico y biotípicos de 5C respecto a AM.

La bondad de la representatividad aludida está avalada, igualmente, por el alto grado de representación alcanzado en algunos grandes grupos: "Ms", "Hbx", "Hrv", "Bpe" y "Msn". En cada uno de éstos, el número de táxones avistados supera el 50\% de todos los presentes en la región. Especial mención merecen las plantas propias de matorrales seriales, que es el agrupamiento que en menos espacio puede ser más 
ampliamente detectado (el $62,5 \%$ de todas las plantas alcarreño-ocañenses fueron avistadas en las cinco cuadrículas prospectadas).

En suma, los principales grandes grupos fitoecológicos de la flora de AM están bien representados en $5 \mathrm{C}$, en la medida que corresponde por el sector geográfico que ocupa cada cuadrícula y, de modo aproximado, con una diversidad ambiental correlativa. Como síntesis y en términos relativos, se comprueba que las hierbas de "Ht" adquieren más notoriedad en el sector centro-meridional de AM, al igual que las vivaces de "Hbx". Las plantas propias del bosque esclerófilo ("Bpe") tienen más relevancia en el sector central y centro-meridional, mientras que las leñosas de "Ms" la tienen en el meridional. Por último, fuera de ambientes de ribera, las hierbas de "Pmh" y "Snn" solo tienen importancia en el sector septentrional.

La semejanza florística entre las cinco cuadrículas es muy variable según los agrupamientos fitoecológicos implicados. Ello responde a las diferentes realidades ambientales que impone la situación geográfica de cada una de ellas dentro del conjunto regional. El análisis particular entre cada par de cuadrículas permite calibrar aún más su representatividad. Por un lado, los valores medios y extremos aportados en la Figura 4 podrían interpretarse en términos modélicos para el conjunto regional, por cuanto sirven como indicadores de la estructura florístico-ecológica interna de muestras geográficas típicas. Por otro lado, permite comprobar que es posible una comparación geográfica aproximada de la riqueza florística entre ellas, si analizando por separado los diferentes componentes, se coteja la presencia o importancia relativa en la cuadrícula de los diferentes ambientes.

El panorama mostrado en este trabajo es el de cinco cuadrículas representativas del conjunto geográfico de AM, por albergar retazos de los elementos paisajísticos más típicos y dominantes (páramo y laderas, con fondos mesohigrófilos asociados). Pero no incorporan otros elementos que, aún de extensión minoritaria, también definen el paisaje alcarreño-ocañense: riberas más completas, medios acuáticos, lacustres, hipersalinos y los extremadamente humanizados. Por ello, bastantes unidades de un kilómetro cuadrado resultarán menos o poco típicas por albergar de manera más decantada y dominante ambientes concretos. En estos casos, evidentemente, se entorpecería considerablemente la comparación geográfica. Sería, pues, de interés analizar en trabajos sucesivos unidades de tamaños mayores $(2 \times 2 \mathrm{~km}, 3 \times 3 \mathrm{~km}$ ó $5 \times 5$ $\mathrm{km})$ que alberguen más geodiversidad y consecuentemente una fitodiversidad correlativa, alcanzando mayor representatividad.

Si a las plantas propias de "Hrv" se unen las de "av" que conviven en ambientes especialmente nitrófilos, se constata que casi una cuarta parte de la flora alcarreñoocañense corresponde a táxones de ámbitos abiertos, de bastante a muy alterados, oportunistas, poco exigentes o de baja calidad ambiental. Ello se ratifica porque en cada recinto analizado los porcentajes son aún más amplios. De hecho, los datos absolutos de la Tabla 1 muestran cómo en un solo recinto de $1 \mathrm{~km}^{2}$ ya puede encontrarse entre el 30 y el 44\% de todas las plantas "Hrv" de AM. Esta elevada concentración de plantas banales en tan poco espacio se explica por el fuerte grado de antropización del territorio, propiciado por una dilatada historia agraria. La vinculación de la flora arvense y ruderal con los usos y aprovechamientos humanos del territorio se presta a 
análisis específicos en estudios futuros que traten acerca de su implantación según las diferentes etapas de ocupación del suelo en la región. Al fin y al cabo este segmento de la flora juega un importante papel en marcar una tendencia florística homogeneizadora en AM. Ello aporta también un cierto aumento de la riqueza general que, quizás, pudiera ser mayor respecto a épocas pasadas en que el hombre todavía no había actuado tan drásticamente sobre el medio. Quedaría por analizar también, en este sentido, el verdadero carácter autóctono de algunas de esas plantas.

En C4 el alto porcentaje relativo de ruderales y arvenses esconde, sin embargo, un cómputo absoluto bastante reducido frente al resto de cuadrículas, donde las cifras son sorprendentemente parecidas. A falta de más datos, parece que el grado de antropización de la cuadrícula villarrubiera es ligeramente menor (no hay cultivos leñosos, probable menor aprovechamiento ganadero en el pasado). Importantes mermas tiene también en la pobre a paupérrima presencia de plantas mesófilas en general, lo que se debe a una casi nula presencia de ambientes edafohigrófilos. Además, probablemente su menor riqueza se deba también a la menor extensión que en este sector de AM tienen las altiplanicies de páramo, así como a la gran extensión que ocupan los espartales (casi la mitad de la superficie), formación poco biodiversa y cuya amplia implantación puede responder a factores histórico-dinámicos.

Se ha observado que las cifras absolutas del espectro biotípico entre algunas cuadrículas son bastante próximas. Y, de otra parte, los desajustes observados han podido ser relacionados claramente con factores geográficos. Ello ha puesto de manifiesto la existencia de pautas alcarreño-ocañenses claras en la composición de formas biológicas, pero además ha sido corroborado por los espectros de otros caracteres vitales más analíticos.

En definitiva, todas estas cifras y porcentajes descriptivos contribuyen a conocer mejor la flora alcarreño-ocañense y sus pautas geográficas más generales. Además, pueden ser útiles para la elaboración de eventuales modelos predictivos que sobre distribución de plantas en AM puedan efectuarse en el futuro.

\section{REFERENCIAS BIBLIOGRÁFICAS}

ALCARAZ, F.; BARREÑA, J.A.; CLEMENTE, M.; GONZÁLEZ, A.J.; LÓPEZ, J.; RIVERA, D. Y RÍOS, S. (2008): Hábitats y sistema de hábitats. En Alcaraz et al.: Manual de interpretación de los hábitats naturales y seminaturales de la Región de Murcia. Tomo 1. Murcia. Dirección General del Medio Ambiente. Región de Murcia, 1-179. http://www.carm.es/siga/enlacpub/publicaciones/monograf/pdf/Tomo\%201\%20Manual\%20de\%20habitats.pdf

ASENSIO, I., GONZÁLEZ, J.A. y VÁZQUEZ, A. (1991): Páramos y campiñas de la Alcarria. En González, J.A. y Vázquez, A. (Coords.): Guía de los Espacios Naturales de Castilla-La Mancha. Toledo. Junta de Castilla-La Mancha. 223-240.

BOLÒS, O. DE (1963): Botánica y Geografía. Memoria de la Real Academia de Ciencias de Barcelona, 34, 443-480. 
BOLÒS, O. DE Y VIGO, J. (1984-2001): Flora dels Països Catalans. Barcelona. Barcino. 4 Vols.

BRAUN-BLANQUET, J.:

(1928). Pflanzensoziologie. Grundzüge der Vegetationskunde. Springer. Berlin. (1979): Fitosociología. Bases para el estudio de las comunidades vegetales. Madrid. Ediciones Blume. 820 p.

CALONGE, A. y RODRÍGUEZ, M. (2008): Geología de Guadalajara. Obras colectivas Ciencias $03 \mathrm{UAH}, 368 \mathrm{p}$.

CASTROVIEJO, S. -Coord. Gral.- (1986-2008): Flora iberica. Plantas vasculares de la Península Ibérica e Islas Baleares. Madrid. Real Jardín Botánico. CSIC. 13 Vols. + borradores y pruebas de imprenta de otros 7 vols. consultados hasta septiembre de 2008 en http://www.rjb.csic.es/floraiberica.

DUVIGNEAUD, P. (1974): La synthèse écologique. Paris. Doin.

EDERRA, A. (1996): Botánica Ambiental Aplicada. Las plantas y el equilibrio ecológico de nuestra tierra. Pamplona. EUNSA. 205 p.

ELLENBERG, H. (1994): Los valores ecológicos de las plantas vasculares (sin “Rubus”). Oviedo. Universidad de Oviedo. Traducción castellana por Hubert Gunnemann. Prólogo por Matías Mayor. 189 p.

FERRERAS, C. (1987): La Phytosociologie comme moyen de diagnostic de l'état du paysage végétal. Colloques Phytosociologiques, 15, 349-359.

FERRERAS, C. (1990): La valoración del estado y dinamismo del paisaje vegetal a través de las comunidades y asociaciones que lo integran. Cadernos de Geografia, 9, 97-109.

GARCÍA-ABAD, J.J. (2006): El inventario florístico con fines geográficos en C.U.T.M. de 1x1 km. Análisis de la riqueza vascular en La Alcarria Occidental y Mesa de Ocaña. Serie Geográfica, 13, 117-150. http://www.geogra.uah.es/inicio/revista/index-13.php http://dspace.uah.es/jspui/handle/10017/1192

GARCÍA-ABAD, J.J. (2009): Geografía de las plantas en La Alcarria Occidental y Mesa de Ocaña (I). Análisis florístico en cinco localidades representativas. Anales de Geografia de la Universidad Complutense, 29 (2), 127-153.

http://revistas.ucm.es/portal/modulos.php?name=Revistas2_Historico\&id=AGU C\&num=AGUC090922.

GARCÍA-ABAD, J.J. y PANAREDA, J.M. (2007-2008): El paisaje alcarreño en Miralrío y su entorno (Guadalajara). Serie Geográfica, 14, 93-108. http://www.geogra.uah.es/inicio/revista/index-14.php http://dspace.uah.es/jspui/handle/10017/2078 
GARCÍA-ABAD, J.J., MALPICA, J.A. y ALONSO, M.C. (2010): Detecting plant spatial patterns, using multidimensional scaling and cluster analysis, in rural landscapes in Central Iberian Peninsula. Landscape and Urban Planning, 95(3): 138150. doi:10.1016/j.landurbplan.

GÉHU, J.M. Y RIVAS-MARTÍNEZ, S. (1981): Notions fondamentales de Phytosociologie. Berichte der Internationalen Symposien der Internationalen Vereinigung für Vegetationskunde: "Syntaxonomie", (Rinteln, 1980), 5-33.

LÓPEZ-SÁEZ, J.A.; CATALÁN, P. Y SÁEZ, Ll. (2002): Plantas parásitas de la Península Ibérica e Islas Baleares. Madrid. Mundi-Prensa. 529 p.

MUCINA, L. (1997): Conspectus of Classes of European Vegetation. Folia Geobotanica \& Phytotaxonomica, 32, 117-172.

NEKOLA, J.C. Y WHITE, P.S. (1999): The distance decay of similarity in biogeography and ecology. Journal of Biogeography, 26, 867-878.

OZENDA, P. (1964): Biogéographie Végétale. Paris. Doin. 374 p.

PEINADO, M.; MONJE, L. y MARTÍNEZ, J.M. (2008): El paisaje vegetal de Castilla-La Mancha. Manual de Geobotánica. Toledo. Editorial Cuarto Centenario. $610 \mathrm{p}$.

RAUNKIAER, C.:

- (1905). Types biologiques pour la géographie botanique. Bull. Acad. Roy.d. Sci. de Danemark, 347-437.

- (1934). The life forms of plants and statistical geography. Oxford. Oxford University Press. 632 p.

RIVAS-MARTÍNEZ, S. (2007): Mapa de series, geoseries y geopermaseries de vegetación de España (Memoria del mapa de vegetación potencial de España). Parte I. Itinera Geobotanica, 17, 5-436.

RIVAS-MARTÍNEZ, S.; FERNÁNDEZ-GONZÁLEZ, F.; LOIDI, J.; LOUSÂ, M. Y PENAS, A. (2001): Syntaxonomical checklist of vascular plant communities of Spain and Portugal to association level. Itinera Geobotanica, 14: 5-341.

http://www.ucm.es/info/cif/book/checklist/checklist_a.htm.

RIVAS-MARTÍNEZ, S.; DÍAZ, T.E.; FERNÁNDEZ-GONZÁLEZ, F.; IZCO, J.; LOIDI, J.; LOUSÂ, M. Y PENAS, A. (2002): Vascular plant communities of Spain and Portugal. Addenda to the syntaxonomical checklist of 2001. Itinera Geobotanica, 15: 5-922.

http://www.ucm.es/info/cif/book/addenda/addenda1_00.htm. 
RUIZ DE LA TORRE -dir.-: Mapa Forestal de España. Escala 1:200.000. Madrid. Dirección General de Conservación de la Naturaleza. Ministerio de Medio Ambiente:

- (1996a). Madrid. Hoja 5-6. Mapa + Memoria (252 p.)

- (1996b). Toledo. Hoja 5-7. Idem (221 p.)

- (1996c). Cuenca-Guadalajara. Hoja 6-6. Idem (313 p.)

RUNHAAR, J.; VAN LANDUYT, W.; GROEN, C.L.G.; WEEDAL, E.J. Y VERLOOYE, F. (2004): Herziening van de indeling in ecologische soortengroepen voor Nederland en Vlaanderen. Gorteria, 30, 12-26.

SMITH, W.G. (1913): Raunkiaer's "Life-forms" and Statistical Methods. Journal of Ecology, 1 (1), 16-26.

TELLO, B. (1986): Relieves tabulares en cuenca sedimentaria. La Mesa de Ocaña (Toledo). En Martínez, E. y Tello, B. (Coords.): Atlas de Geomorfología. Madrid. Alianza Editorial, 127-136.

TRICART, J. (1965): Principes et Méthodes de la Géomorphologie. Masson, Paris.

VELARQUE, R.; MÉDAIL, F. Y ABOUCAYA, A. (2001): Valeur prédictive des types biologiques pour la conservation de la flore méditerranéenne. C.R. Acad. Sci. Paris, Sciences de la vie, 324: 1157-1165.

Páginas Web

http://www.synobiosys.alterra.nl/ecotopen. SynBioSys. Syntaxonomisch Biologisch Systeem. Ecotopesysteem van Nederland en Vlaanderen (Ecotopos de Holanda y Flandes). 